University of Nebraska - Lincoln

DigitalCommons@University of Nebraska - Lincoln

\title{
Positive Psychological Capital: Measurement and Relationship with Performance and Satisfaction
}

Fred Luthans

University of Nebraska - Lincoln, fluthans1@unl.edu

Bruce J. Avolio

University of Nebraska - Lincoln, bavolio@u.washington.edu

James B. Avey

Central Washington University, aveyj@cwu.edu

Steven M. Norman

Mesa State College, snorman@mesastate.edu

Follow this and additional works at: https://digitalcommons.unl.edu/leadershipfacpub

Part of the Management Sciences and Quantitative Methods Commons

Luthans, Fred; Avolio, Bruce J.; Avey, James B.; and Norman, Steven M., "Positive Psychological Capital: Measurement and Relationship with Performance and Satisfaction" (2007). Leadership Institute Faculty Publications. 11.

https://digitalcommons.unl.edu/leadershipfacpub/11

This Article is brought to you for free and open access by the Leadership Institute at DigitalCommons@University of Nebraska - Lincoln. It has been accepted for inclusion in Leadership Institute Faculty Publications by an authorized administrator of DigitalCommons@University of Nebraska - Lincoln. 


\title{
Positive Psychological Capital: Measurement and Relationship with Performance and Satisfaction
}

\author{
Fred Luthans and Bruce J. Avolio \\ Gallup Leadership Institute, Department of Management, \\ University of Nebraska-Lincoln \\ James B. Avey \\ Department of Management, \\ Central Washington University \\ Steven M. Norman \\ Department of Management, Mesa State College \\ Corresponding author - Fred Luthans, Department of Management, \\ University of Nebraska-Lincoln, Lincoln, NE 68588-0491; fluthans1@unl.edu
}

\begin{abstract}
Two studies were conducted to analyze how hope, resilience, optimism, and efficacy individually and as a composite higher-order factor predicted work performance and satisfaction. Results from Study 1 provided psychometric support for a new survey measure designed to assess each of these 4 facets, as well as a composite factor. Study 2 results indicated a significant positive relationship regarding the composite of these 4 facets with performance and satisfaction. Results from Study 2 also indicated that the composite factor may be a better predictor of performance and satisfaction than the 4 individual facets. Limitations and practical implications conclude the article.
\end{abstract}

In a special issue of the American Psychologist, Sheldon and King (2001, p. 216) point out that "Positive psychology revisits the 'average person' with an interest in finding out what works, what is right, and what is improving." Like positive psychology, which does not claim to have discovered the importance of positivity (e.g., see Peterson, 2006), the recently emerging positive organizational behavior field recognizes that much of the early history (e.g., Herzberg, 1966; Maslow, 1954; McGregor, 1960) and contemporary theories and research (e.g., job satisfaction, organizational commitment, positive affectivity, core self-evaluations, organizational citizenship, intrinsic motivation, humor, self-determination, organizational justice, among others) are 
positively oriented. Nevertheless, analogous to, and drawing from, the positive psychology literature, the term positive organizational behavior is intended to identify a newly emerging focus on a positive approach to developing and managing human resources in today's workplace (for recent reviews of this emerging literature, see Luthans \& Youssef, 2007; Luthans, Youssef, \& Avolio, 2007).

Positive organizational behavior has been defined as "the study and application of positively oriented human resource strengths and psychological capacities that can be measured, developed, and effectively managed for performance improvement" (Luthans, 2002b, p. 59; also see Nelson \& Cooper, 2007; Turner, Barling, \& Zaharatos, 2002; Wright, 2003). In addition, to differentiate from other positive approaches reported in both the academic and practitioner literatures, the following criteria were set for including constructs in this definition of positive organizational behavior: (a) grounded in theory and research; (b) valid measurement; (c) relatively unique to the field of organizational behavior; (d) state-like and hence open to development and change as opposed to a fixed trait; and (e) have a positive impact on work-related individual-level performance and satisfaction (Luthans, 2002a, 2002b; Luthans et al., 2007).

Using these criteria, the positive psychological constructs that have been determined to meet the inclusion criteria so far include hope, resilience, optimism, and self-efficacy, and when combined, represent what has been termed psychological capital or PsyCap (Luthans \& Youssef, 2004; Luthans et al. 2007). This composite construct has been defined as "an individual's positive psychological state of development and is characterized by: (1) having confidence (self-efficacy) to take on and put in the necessary effort to succeed at challenging tasks; (2) making a positive attribution (optimism) about succeeding now and in the future; (3) persevering toward goals and, when necessary, redirecting paths to goals (hope) in order to succeed; and (4) when beset by problems and adversity, sustaining and bouncing back and even beyond (resilience) to attain success" (Luthans et al., 2007, p. 3).

Besides the traditional use in economics and finance, the term capital has also been used to represent the value of human resources (human capital) as well as with other concepts (e.g., intellectual capital, social capital, cultural capital).We simply use the term psychological capital here to represent individual motivational propensities that accrue through positive psychological constructs such as efficacy, optimism, hope, and resilience. Positive psychologist Csikszentmihalyi (as quoted in Kersting, 2003, p. 26) noted that such psychological capital "is developed through a pattern of investment of psychic resources that results in obtaining experiential rewards from the present moment while also increasing the likelihood of future benefit. . . It's about the 
state of the components of your inner life. When you add up the components, experiences and capital, it makes up the value." The "components" in our case are efficacy, optimism, hope, and resilience.

The purpose of the present studies is to examine the measurement properties of a survey instrument used to assess such identified psychological capital and to determine its relationship with job satisfaction and performance outcomes. After first providing theoretical support for developing and testing a higher-order factor, we present preliminary results on the psychometric properties of the designed measure and empirical tests of the study hypotheses.

\section{Psychological Capital as a Distinctive Construct}

The beginning point in our research is to clearly define the unit of analysis (Klein, Dansereau, \& Hall, 1994). As presented here, the study of this higherorder construct is focused on the individual as the level of analysis. Specifically, this individual level is not intended to rule out the potential for dyadic, group, or organizational levels of analysis for a type of team or "collective" PsyCap in the future but is simply intended to clarify the scope of the present study.

Because PsyCap is being proposed as a higher-order construct, it first must meet the conceptual and empirical criteria of being distinctive (Judge, Van Vianen, \& DePater, 2004; Schwab, 1980). Conceptually, one way that this higherorder construct can be differentiated from other constructs in positive psychology (Peterson, 2006; Peterson \& Seligman, 2004; Snyder \& Lopez, 2002) involves focusing on the state-like versus trait-like distinction made in this literature. Specifically, whereas PsyCap uses the inclusion criterion of being "state-like," the Peterson and Seligman (2004) signature character strengths and virtues (CSVs) must meet the criterion of being "trait-like - an individual difference with demonstrable generality and stability" (Seligman, Steen, Park, \& Peterson, 2005, p. 411). In addition to CSVs, the state-like nature of PsyCap also differentiates it from positively oriented organizational behavior traitlike constructs such as "Big Five" personality dimensions (Barrick \& Mount, 1991) or core self-evaluations (Judge \& Bono, 2001; Judge, Van Vianen, \& DePater, 2004).

Although trait theories have a long history in psychology and are experiencing a resurgence of interest in organizational behavior and human resource management literatures, the notion of states has been mainly restricted to discussions of moods and emotions. States and traits are often considered as independent, dichotomous categories of constructs. Nevertheless, in defining what constitutes PsyCap we portray states and traits along a continuum 
largely determined by the relative degrees of stability in measurement and openness to change and development (Avolio \& Luthans, 2006; Luthans \& Avolio, 2003; Luthans et al., 2007). Recognizing that different theorists will take different positions on the placement of a given construct along a statetrait continuum (e.g., emotions or positive affectivity have been placed at both extremes in the literature), the following continuum is proposed as a heuristic to clarify what is meant by "state-like":

(1) Positive States - momentary and very changeable; represents our feelings. Examples could include pleasure, positive moods, and happiness.

(2) "State-Like" - relatively malleable and open to development; the constructs could include not only efficacy, hope, resilience, and optimism, but also a case has been made for positive constructs such as wisdom, well-being, gratitude, forgiveness, and courage as having "state-like" properties as well (Luthans et al., 2007).

(3) "Trait-Like" - relatively stable and difficult to change; represents personality factors and strengths. Examples could include the Big Five personality dimensions, core self-evaluations, and character strengths and virtues (CSVs).

(4) Positive Traits - very stable, fixed, and very difficult to change. Examples could include intelligence, talents, and positive heritable characteristics.

Notice that the PsyCap constructs fit in the continuum as being "state-like," that is, they are not as stable and are more open to change and development compared with "trait-like" constructs such as Big Five personality dimensions or core self-evaluations, but importantly that they also are not momentary states.

This state versus trait debate has long been discussed in the psychology literature (e.g., see Allen \& Potkay, 1981; Zuckerman, 1983), and relevant previous research can be found in the work of Conley (1984). In an analysis of longitudinal research studies, Conley compared the test- retest reliabilities between intelligence, personality, and what he describes as self-opinion constructs (e.g., life satisfaction and self-esteem). Results support that such psychological constructs are best understood as being more or less stable. Specifically, Conley (1984, p. 11) found a "hierarchy of consistency" with intelligence and personality being more stable over time than self-opinion.

Besides this classic work on the stability of individual differences, Wright (2007) has recently called for distinguishing the relative temporal difference between states and traits in research focusing on positive organizational behavior (also see Chamberlain \& Zita, 1992; Cropanzano \& Wright, 1999). Such research and analysis provide support for the notion of a continuum of stability of positive constructs. In particular, this is supportive of our proposal that 
although each component of PsyCap may have some stability over time, compared with personality traits or core self-evaluations, they are expected to not be as stable and therefore are state-like and open to change and development.

Both theory-building and prior research on hope, resilience, optimism, and efficacy supports that they are developable. As examples, Bandura (1997) has demonstrated strategies to increase self-efficacy (also see Bandura, 2000). Snyder (2000) provides evidence that hope is developable and published the state-hope scale (Snyder et al., 1996). Although known for their earlier work on dispositional optimism, Carver and Scheier (2005) more recently discuss strategies to develop optimism, and Shifren and Hooker (1995) have demonstrated its situational measurement. Seligman (1998) features "learned optimism" in his widely recognized book by this title and offers evidence to support its development. Masten and Reed (2002) likewise discuss successful strategies for resilience-based developmental interventions, and Wagnild and Young (1993) have developed a state-like measure of it. Each of these contributions in the positive psychology literature have supported that these four constructs can be developed. There is also some preliminary evidence that when these four constructs are combined into a higher-order construct it can be considered state-like and hence may be developable (Luthans, Avey, \& Patera, in press; Luthans, Avey, Avolio, Norman, \& Combs, 2006).

Because PsyCap is just emerging, there have not yet been published studies to empirically demonstrate its discriminant validity in relation to other established constructs. Therefore, in the first study described below we will use one of our samples to assess the discriminant validity of PsyCap in relation to more trait-like constructs such as Big Five personality dimensions and core self-evaluations (Judge \& Bono, 2001; Judge, Erez, Bono, \& Thoresen, 2003; Judge et al., 2004). Nevertheless, in addition to empirically differentiating PsyCap from other established positive constructs, there is also a need to establish its own theoretical foundation.

\section{Theoretical Background}

Each of the four components has considerable theory and research that can contribute to developing an integrative theoretical foundation for PsyCap. For example, Snyder and colleagues (1991, p. 287) define hope as a "positive motivational state [italics added] that is based on an interactively derived sense of successful (a) agency (goal directed energy) and (b) pathways (planning to meet goals)." In this way, as a psychological construct, hope consists of three major conceptual foundations: agency, pathways, and goals. The agency component of hope can be thought of as having the will to accomplish the in- 
tended or desired effect (Snyder, 2000, 2002; Snyder et al., 1996). Therefore, hope involves the agency or motivational energy to pursue a goal, which, like efficacy, is a state. In addition, hope also involves the pathways that include not only identifying goals and subgoals, but also alternative ways to reach those goals. Those high in hope utilize contingency planning as they forecast obstacles to achieving goals or subgoals and proactively identify multiple pathways to attain the targeted goal (Snyder, 2000). In other words, hope constitutes the will to succeed and the ability to identify, clarify, and pursue the way to success (Snyder, 2000).

Determining the construct validity of hope is critical to applying it in combination with other dimensions of PsyCap. Theory building and research have demonstrated hope to be conceptually convergent but also distinct from other positive constructs (Snyder, 2002 for a detailed analysis) and has been empirically demonstrated to have discriminant validity in relation to similar positive constructs (Bryant \& Cvengros, 2004; Carifio \& Rhodes, 2002; Magaletta \& Oliver, 1999; Youssef \& Luthans, in press).

Although hope has considerable face validity and intuitive appeal, along with research support for the relationship between hope and academic, athletic, and health outcomes (Snyder, 2000, 2002), to date very few studies have explored its impact in the workplace. For example, Adams et al. (2002) in an ongoing survey found that organizations with respondents reporting higher levels of hope tended to be more successful than those with lower levels of hope. Peterson and Luthans (2003) found fast-food store managers' level of hope correlated with financial performance of their unit and employee retention and job satisfaction. In a recent study, the hope level of Chinese factory workers was also found to be related to their supervisory-rated performance and merit salary increases (Luthans, Avolio, Walumbwa, \& Li, 2005).

Besides these initial findings on relationships with performance, there is also some evidence that hope may be related to desirable work attitudes. For example, recent studies have found that the hope levels of production workers in a small midwestern factory were related to their job satisfaction and organizational commitment (Larson \& Luthans, 2006). In a large cross-sectional sample of employees, hope was related to their satisfaction, organizational commitment, and work happiness (Youssef \& Luthans, in press).

In positive psychology, resilience is characterized by positive coping and adaptation in the face of significant risk or adversity (Masten, 2001; Masten \& Reed, 2002). Applied to the workplace, resilience is defined as the "positive psychological capacity to rebound, to 'bounce back' from adversity, uncertainty, conflict, failure, or even positive change, progress and increased responsibility" (Luthans, 2002a, p. 702). Empirical studies have shown that positive emotions enhance resilience in the face of negative events, which re- 
flect its state-like quality (Tugade, Fredrickson, \& Barrett, 2004). Clinical psychologists also note that resilience can increase and even grow when the individual returns to levels above homeostasis after an adverse event (Richardson, 2002). In short, individuals may actually become more resilient to an adverse situation each time they effectively bounce back from a previous setback. Such positive reactions have been found in studies of emotions to have upward spiraling effects (Fredrickson \& Joiner, 2002). We propose that this is where the interaction and synergies with hope, optimism, and self-efficacy may take the level of resilience beyond that of homeostasis (Richardson, 2002). For example, in discussing the positive impact of efficacy, Bandura (1998, p. 62) notes, "Success usually comes through renewed effort after failed attempts. It is resiliency of personal efficacy that counts."

Although to date there has been little research evidence on such resilience in the workplace, Luthans et al. (2005) did find a significant relationship between the resilience of the Chinese workers who were undergoing significant change and transformation and their rated performance; Maddi (1987) found that hardy, resilient employees in a firm undergoing a massive downsizing maintained their health, happiness, and performance; Larson and Luthans (2006) found the factory workers' resiliency related to their job satisfaction; and Youssef and Luthans (in press) found that employees' level of resilience related to their satisfaction, commitment, and happiness.

Like hope, optimism is commonly used in everyday language, but also like hope, in positive psychology it has a very specific meaning with theory and research addressing this positive construct. Drawing from attribution theory, Seligman (1998) defines optimists as those who make internal, stable, and global attributions regarding positive events (e.g., task accomplishment) and those who attribute external, unstable, and specific reasons for negative events (e.g., a missed deadline). Therefore, optimism as a facet of PsyCap is associated with a positive outcome outlook or attribution of events, which includes positive emotions and motivation and has the caveat of being realistic (Luthans, 2002a). As used here, optimism is not just an unchecked process without realistic evaluation (Schneider, 2001). Realistic optimism includes an evaluation of what one can and cannot accomplish in a particular situation and hence adds to one's efficacy and hope. As Peterson (2000) notes, realistic optimism is very dynamic and changeable and is considered state-like.

In relation to self-efficacy, Bandura (1998, p. 56) notes that "evidence shows that human accomplishments and positive well-being require an optimistic sense of personal efficacy to override the numerous impediments to success." In assessing the similarities and differences between hope and optimism, Snyder (2002, p. 257) notes that, similar to hope, "optimism is a goalbased cognitive process that operates whenever an outcome is perceived as 
having substantial value." Seligman (1998) has found that optimism, when directly applied to the workplace, had a significant and positive relationship with performance of insurance sales agents, and in the study of the Chinese factory workers, their optimism was found to have a significant relationship with their rated performance (Luthans et al., 2005). Youssef and Luthans (in press) reported that employees' optimism related to their performance evaluations and their job satisfaction and work happiness.

Self-efficacy has been argued to best meet the inclusion criteria for PsyCap (Luthans, Youssef, \& Avolio, 2007). Self-efficacy represents a positive belief (not ability per se nor outcome expectancy) and was defined for the workplace by Stajkovic and Luthans (1998b, p. 66) as "the employee's conviction or confidence about his or her abilities to mobilize the motivation, cognitive resources or courses of action needed to successfully execute a specific task within a given context." In results from a comprehensive meta-analysis, selfefficacy was found to have a strong positive relationship with work-related performance (Stajkovic \& Luthans, 1998a; also see Bandura, 2000; Bandura \& Locke, 2003).

In terms of this study, we broaden the use of self-efficacy beyond a single task to the work domain. Employees may be more or less efficacious in the work domain such as a group of more specific tasks. As Bandura (1998, p. 53) has concluded, "Comparative studies show that domain linked measures of perceived efficacy are good predictors of motivation and action." Although this broadens the conceptualization of very specific task efficacy, it does not extend across domains or to all of life such as is portrayed by generalized selfefficacy (e.g., see Sherer et al., 1982). As applied to the higher-order construct of PsyCap, we draw from Bandura's (1998, p. 53) position that, "The efficacy belief system is not an omnibus trait."

\section{Theoretical Commonalities}

It is important that each of the four positive constructs reviewed above has been shown to have conceptual independence (Bandura, 1997; Luthans \& Jensen, 2002; Luthans et al., 2007; Snyder, 2000, 2002) and empirically based discriminant validity (Bryant \& Cvengros, 2004; Carifio \& Rhodes, 2002; Magaletta \& Oliver, 1999; Youssef \& Luthans, in press). By the same token, we propose that there also may be a common, underlying link that runs between them and ties them together, that is, a higher-order core factor. As indicated in the definition of PsyCap, this commonality or underlying link is a mechanism shared across each of the facets that contribute to a motivational propensity to accomplish tasks and goals. A relevant discussion of conceptual frameworks provided by Law and colleagues (1998) describes the nature and 
epistemology of multidimensional constructs such as the proposed higherorder factor PsyCap. Specifically, they describe how multidimensional constructs may have components relating to a core underlying factor whereby the shared variance or commonality between each facet comprises the higherorder factor. This concept is not new in the consideration of individual differences. For example, a number of years ago Watson and Clark (1984, p. 465) argued, "Distinct and segregated literatures have developed around a number of personality traits that, despite different names, nevertheless inter-correlate so highly that they must be considered measures of the same construct." In other words, distinct psychological constructs may have, at their core, common processes driving motivation and behavior. Using such arguments, we propose the higher-order factor of PsyCap may represent the common source of variance (i.e., common mechanistic processes) connecting the four constructs of hope, optimism, resilience, and self-efficacy.

The nature of a higher-order factor being made up of distinct components as proposed here is common in organizational behavior research. As examples, constructs such as transformational leadership were composed of charisma, individual consideration, intellectual stimulation, and inspirational motivation (Avolio, Bass, \& Jung, 1999); empowerment composed of meaning, competence, self-determination and impact (Spreitzer, 1995); and core self-evaluations consisting of self-esteem, generalized efficacy, locus of control, and emotional stability (Judge \& Bono, 2001) can each be considered higher-order factors. They have distinct dimensions, which are indicators of a "higher-order" construct or an overall core factor.

In the case of PsyCap, there is both conceptual and preliminary research support for the proposed higher-order factor. As indicated in the above discussion of each of the four facets, Bandura $(1997$, p. 3) concludes that those high in self-efficacy will be more resilient to adversity, and Snyder (2000, pp. 39-40) found that those high in hope tend to be more confident on specific tasks (self-efficacy) and are quickly able to bounce back (resilience) after temporary hopelessness.

Empirical evidence from the Chinese factory workers study noted previously found that each of their levels of hope, optimism, and resilience related at about the same level to performance outcomes. Yet, the combination of these three facets, indicating the shared mechanisms between them, had a higher relationship with rated performance than any one of them individually (Luthans et al., 2005). Therefore, although each of the components has demonstrated discriminant validity across multiple samples when compared with each other (Bryant \& Cvengros, 2004; Carifio \& Rhodes, 2002; Magaletta \& Oliver, 1999; Youssef \& Luthans, in press), there is also some beginning evidence to support an overall core construct (Luthans et al., 2005).We propose that even though hope, resilience, optimism, and self-efficacy may have 
conceptual independence and discriminant validity, they may also make a unique theoretical and measurable contribution to a higher order core construct of PsyCap, representing one's positive appraisal of circumstances and probability for success based on motivated effort and perseverance.

The definition of PsyCap, presented in the introduction and described above as a core factor, we propose will have a greater relationship with performance and job satisfaction than the four individual components that comprise it. By considering self-efficacy, hope, optimism, and resilience as important facets of PsyCap rather than focusing on any one individual facet in particular, we expect their combined motivational effects will be broader and more impactful than any one of the constructs individually. For example, optimistic self-efficacy is broader and more impactful than just optimism or selfefficacy. Each facet includes both unique and common cognitive and motivational processes that enable performance. Nevertheless, when combined with each other, the cognitive and motivational processes are expected to be enhanced. Therefore, theoretically considering and operationalizing each construct as facets of overall PsyCap (i.e., a latent factor with four facets as indicators) allows for broader and potentially more impactful cognitive and motivational processes to be engaged in work performance.

As an example of the above, if an efficacious employee is a good performer because of accepting significant challenges and expending the necessary effort to achieve goals (Bandura, 1997), then an efficacious and hopeful employee (who not only accepts challenges and puts out effort to achieve goals, but also identifies subgoals and pathways to achieve those goals, forecasts obstacles, and has contingency plans to overcome such obstacles by pursuing multiple pathways) should perform even better and have higher satisfaction.

The same could be said of the emergent effects of resilience and optimism when in combination with self-efficacy and hope. For example, if employees demonstrating resilience with bounce-back capacity are also efficacious and hopeful, they should be more confident to persist and put forth the necessary effort, while pursuing alternate pathways to return to their original level. With this combination, they may come back above and beyond where they were before the adverse event. Also, the employee with greater capacity for optimism may have a positive perspective but combined with self-efficacy and hope will also have the confidence and persistence to pursue alternative pathways when necessary to actually attain optimistic goals. The more resilience employees can access and use to bounce back, the more likely they can recover from set backs at work. Nevertheless, when combined with hope, resilient employees will also have determined the pathways of how to bounce back and beyond, while also building levels of self-efficacy by showing they can overcome a significant challenge, and optimism to do so in the future. In 
other words, we propose that employees who embody high levels of overall PsyCap may be stronger performers because of the number and level of positive psychological constructs manifested through their cognitions, motivation, and, ultimately, their behavior than would those who only exhibit hope, or resilience, or optimism, or self-efficacy in a given situation.

Although primarily aimed at performance improvement, employees with higher levels of PsyCap may also be more satisfied with their job and their leaders. For example, the previously noted exploratory study of the production workers at the small factory found a relationship with their score on PsyCap and their job satisfaction (Larson \& Luthans, 2006). In general, employees who exhibited higher levels of hope were found to be more satisfied perhaps because through their jobs they were enabled to have both the motivation and a plan to make the best of their situation (e.g., see Youssef \& Luthans, in press). Yet, we propose that even higher satisfaction may occur when such hope is accompanied by optimism and/or self-efficacy in doing that job and the resilience to respond favorably to any setbacks. Because of the proposed higher-order nature of the four components when taken together, PsyCap should be related to employee performance and satisfaction above and beyond each individual construct's bivariate relationships with performance and satisfaction.

On the basis of this emerging theoretical foundation for PsyCap, we derive our study hypotheses as follows:

Hypothesis 1: Employees' level of PsyCap will be positively related to their performance and job satisfaction.

Hypothesis 2: Employees' level of PsyCap will have a relatively stronger relationship to their performance and job satisfaction than each of the individual facets of hope, resilience, optimism, and self-efficacy.

\section{Methods}

Two studies were conducted to analyze the measure of PsyCap and test the hypotheses. Study 1 utilized three samples of management students with an age range that can be termed emerging adults (Arnett, 2000). Study 2 used two separate samples of employees in both service and high-technology manufacturing environments to test the hypotheses in the field. With Study 1, we first review the initial psychometric properties with Sample 1 examining the factor structure, Sample 2 examining the nomological network, and Sample 3 examining the test-retest statistics and additional discrimination from related constructs. With Study 2, we test hypotheses with two independent sam- 
ples of manufacturing engineers (Sample 1) and insurance service employees (Sample 2). Each sample is generally discussed in this order below, and for more clarity when referring to the two samples in Study 2, we will use the terms "high tech manufacturing" and "services."

\section{Samples for Study 1}

The first sample in Study 1 consisted of 167 management students from a large state university in the Midwest. These participants had an average age of 22.25 years $(S D=1.41)$ and $67 \%$ were men. The second sample of Study 1 was drawn about 5 months later from different management students at the same university and from a second large university from the mideastern United States. These 404 participants in this second sample were similar to the first in terms of demographics (average age 21.10 years, $S D=2.66$ and $58 \%$ were men). Finally, to investigate the stability of the PsyCap measure, we administered a series of scales at three points in time over the course of 4 weeks to 174 different management students from the same midwestern university noted above.

\section{Samples for Study 2}

The high-tech manufacturing sample for Study 2 consisted of engineers and technicians from a very large (Fortune 100, over 150,000 employees) firm. These 115 participants averaged $44.83(S D=7.31)$ years and $80 \%$ were men. The service sample for Study 2 was made up of employees in all functions and levels of a midsized (about 900 employees) insurance services firm (i.e., they service insurance policies from other firms). These 144 subjects averaged $33.79(S D=10.85)$ years and $65 \%$ were women.

\section{Procedures for the Studies}

In Study 1, management students consenting to participate in an "Organizational Behavior and Leadership" project were provided a Web address to register. They were then sent a unique password via e-mail that allowed them to $\log$ in and take a short questionnaire survey. Following the recommendations of Podsakoff and colleagues (Podsakoff, MacKenzie, Lee, \& Podsakoff, 2003) to reduce same source/common methods bias problems from questionnaire surveys, we administered the study survey at two points in time. The first part of the survey containing the predictor study variables was taken in the first session. Then a week later, they logged back in and completed the survey that included performance and satisfaction study variables. 
The on line method was also used in Study 2 to gather survey data on the predictor variables from those consenting to participate in the insurance service firm. All participants were advised through informed consent that company performance evaluations would be linked with their survey responses to inform organizational research. The most recent performance data on participants in this sample were gathered from the human resources department a month after the survey was taken. This one month lag was deemed to be appropriate because of our proposed statelike properties of PsyCap. The basis for the appropriateness of a month can be found in our introductory discussion of the state-like nature of PsyCap. Specifically, in contrast to unstable states such as pleasure, positive moods, and happiness, the "state-like" PsyCap is proposed to be relatively more stable and we used one month as a reasonable period of time for conducting a preliminary examination of the performance relationship with PsyCap.

For the high-tech manufacturing firm in Study 2, members of the engineering group were sent an "Attendance Optional" meeting notice. During this meeting, the chief engineer (first level executive) announced an opportunity to be a part of an "Organizational Behavior and Leadership" project. Those participating agreed to the informed consent and linking their survey responses to the firm's performance evaluations. Administered on site by the outside researcher to assure confidentiality, they completed the survey containing the predictor variables. Similar to the service firm, the most recent performance data for these participants in the high-tech manufacturing firm were again gathered a month after the survey from the human resources department. As described above, this one month was deemed an appropriate period of time given the state-like nature of PsyCap. These data were based on both objective and rated performance already being collected by the organization.

\section{PsyCap Measure}

The members of the research team for this study, with additional consultation and input from colleagues doing similar research, selected the scales for each of the four positive facets. The selection criteria were not only that the scale had to demonstrate reliability and validity in the published literature and have relevance to the workplace, it also had to either be developed as, or capable of, measuring the state-like constructs making up PsyCap. The four scales that were determined to best meet these criteria were (a) hope (Snyder et al., 1996); (b) resilience (Wagnild \& Young, 1993); (c) optimism (Scheier \& Carver, 1985); and (d) self-efficacy (Parker, 1998). 
Each of these four selected scales have considerable psychometric support across multiple samples in prior research and have also been verified in workplace studies by themselves or in combination (e.g., Jensen \& Luthans, 2006; Larson \& Luthans, 2006; Luthans et al., 2005; Peterson \& Luthans, 2003; Youssef \& Luthans, in press). As far as meeting the statelike selection criterion is concerned, the selected hope scale of Snyder et al. (1996) was specifically developed and supported as "State Hope." Although the Scheier and Carver (1985) scale is associated with dispositional optimism (or life orientation), this instrument has also been demonstrated to be capable of measuring state-like optimism (Shifren \& Hooker, 1995). Resiliency and efficacy scales such as those selected are generally associated with state-like measurement, but the Parker (1998) efficacy scale departs from the specific task magnitude and strength measurement suggested by Bandura (1997). Nevertheless, as explained in the previous discussion of efficacy, the Parker scale (1998) is specific to the work domain, and its use of a Likert-type scale rather than traditional magnitude and strength has considerable psychometric support as a measure of efficacy (Maurer \& Pierce, 1998).

The four selected measures provided the foundation and pool of items from which the research group developed the PsyCap questionnaire (PCQ) measure. Two major criteria were used by the group in constructing the PCQ. First, we proposed that each of the four constructs would have equal weight, so the best six items from each of the four measures would be selected. Second, the selected items should have face and content validity with being statelike and relevant to the workplace or adaptable to wording changes to make them relevant. The group reached agreement on the 24 items and put the response choices into a 6 -point Likert-type scale $(1=$ strongly disagree, $2=$ disagree, $3=$ somewhat disagree, $4=$ somewhat agree, $5=$ agree, $6=$ strongly agree). To facilitate the state-like framing, the PCQ asks the respondent to describe how you think about yourself right now.

The PCQ in its entirety can be found in Luthans, Youssef, and Avolio (2007); here are some sample items: (a) efficacy: "I feel confident in representing my work area in meetings with management" and "I feel confident helping to set targets/goals in my work area"; (b) hope: "Right now I see myself as being pretty successful at work" and "If I should find myself in a jam at work, I could think of many ways to get out of it"; (c) resilience: "When I have a setback at work, I have trouble recovering from it, moving on (R)" and "I usually take stressful things at work in stride"; and (d) optimism: "I always look on the bright side of things regarding my job" and "If something can go wrong for me work-wise, it will (R)." 


\section{Reliability of Measures}

The Cronbach alphas for each of the four 6-item adapted measures and the overall PsyCap measure for the four samples were as follows: hope (.72, .75, $.80, .76)$; resilience $(.71, .71, .66, .72)$; self-efficacy $(.75, .84, .85, .75)$; optimism $(.74, .69, .76, .79)$; and the overall PsyCap $(.88, .89, .89, .89)$. Although the optimism scale in the second sample (.69) and the resilience scale in the third sample (.66) did not reach generally acceptable levels of internal consistency, the reliability of the overall PsyCap measure in all four samples was consistently above conventional standards.

\section{Performance Measures}

Study 1 used a 4-item self-rated performance measure (e.g., How would you rate your performance/effectiveness as compared with your peers?). The scale was framed by asking participants to rate their performance in their current job over the past week. If they were not employed then, they were asked to rate their academic performance over the past week. This measure demonstrated adequate reliability $(a>.70)$ and was only used to examine the nomological network of PsyCap and, because it was a self-measure, was not used to test any hypotheses.

Study 2, on the other hand, used actual performance evaluations that were gathered independent of the study. Hence, the performance measures were based on objective data and managerial ratings of participants obtained from the human resources department records of the two organizations studied. For the high-tech manufacturing firm, also as prescribed by its appraisal process, each participant's performance measure included a sum of ratings based on quality and objective quantity of their work on electrical subsystem designs including error and rejection rates, meeting the schedule, complexity of assignment, and ability to work with peers. This measure was then cross-checked by all managers within a given job family to ensure consistency in performance ratings across work units. Although each engineer may be performing a set of slightly different tasks in this appraisal process, all participants had similar job descriptions, performance evaluation criteria, and were considered peers in that they had similar jobs in term of procedures and deliverables. As consistent with the organization's policy, managers of job families (up to 15 managers) normalized the ratings to settle on a final performance rating.

The insurance services firm provided the most recent performance rating for each participant 1 month after they had taken the PsyCap survey. The ratings were based on the most recent month of performance (i.e., after the survey had been administered). These data consisted of input from both objec- 
tive performance data (e.g., number of claims processed) and their manager's overall evaluation as prescribed by the firm's performance appraisal process in one total composite score.

\section{Job Satisfaction Measure}

In addition to performance, this study also examined the relationship of PsyCap with job satisfaction. As commonly used in organizational behavior research (e.g., Judge \& Bono, 2001), all of our samples but one used a 3-item scale adapted from Hackman and Oldham (1980) using the same 1-6 rating as for the PsyCap measure. This satisfaction scale had high internal reliability, Cronbach alphas $(.89, .87$, and .86$)$, for the three samples. To meet its concern with the length of the survey, the high-tech manufacturing sample used a one item overall job satisfaction question ("How satisfied are you with your job?").

We also gathered affective organizational commitment (Allen \& Meyer, 1996; 1990) data in Sample 1 of Study 1. The purpose of gathering these additional data was to aid in determining the discriminant validity of the PsyCap instrument and to generate a better understanding of the nomological network of constructs for the proposed PsyCap measure. The affective dimension of organizational commitment has been noted for its unique contribution, given it captures the employee's affective desire to remain with the organization versus a calculative conclusion (Judge \& Bono, 2000) and is often used as a single dimension in organizational research (e.g., Bono \& Judge, 2003; Judge $\&$ Bono, 2000). On the basis of face and content validity, the research team selected four items from Allen and Meyer's affective commitment scale for this measure. An example item is "I would be quite pleased to spend the rest of my life working for this organization." These items demonstrated a reliability coefficient of 89 .

We gathered the job satisfaction data for all samples and affective organizational commitment for Sample 1 of Study 1 one week later than the predictor variables to minimize potential same-source effects/bias. As noted by Podsakoff et al. (2003, p. 887), this temporal separation procedure "makes it impossible for the mindset of the source or rater to bias the observed relationship between the predictor and criterion variable, thus eliminating the effects of consistency motifs, implicit theories, social desirability tendencies" and other individual attributes that may influence or bias the responses. In addition to the temporal strategy of data collection, to confirm the accuracy of the self-reported demographic data, we randomly cross-checked against actual personnel records and found no inconsistencies. 


\section{Psychometric Analyses}

Using guidelines offered by Schwab (1980) and Pedhazer and Schmelkin (1991), we determined several requisite conditions for the PsyCap measure. These parallel the conditions and guidelines used for determining the core self-evaluations construct of Judge and colleagues (2003). Specifically, the following needed to be established: (a) content validity such that each facet is equally represented in the overall PsyCap instrument, which we established as discussed above in constructing the 24-item questionnaire; (b) sufficient PsyCap scale reliability; (c) PsyCap must have a unitary factor structure consistent with the proposed latent construct; (d) convergent validity with other theoretically similar constructs; (e) discriminant validity with those constructs with which it is supposed to differ; (f) empirical validity with appropriate outcome constructs such as being significantly related to performance and job satisfaction; and finally, (g) predicts variance in these outcomes (i.e., performance and satisfaction) beyond other similar constructs (in this case Conscientiousness, Extraversion, and core self-evaluation traits).

\section{Results}

\section{Confirmatory Factor Analysis}

To confirm the expected higher-order factor of PsyCap, we conducted a confirmatory factor analysis on the data from Study 1 using commonly accepted procedures recommended by Hinken (1995). Because maximum likelihood estimation was utilized for this confirmatory factor analysis, it was necessary to analyze the multivariate normality present in the data collected for this study. Most items from the PsyCap measure had values below one, and all items were well below two for both skewness and kurtosis. Although no clear-cut standards are specified, those below three are generally accepted for skewness, and items below 10 are generally accepted for kurtosis (Kline, 2005). In addition, both Kolmogorov-Smirnov and Shapiro-Wilks tests of data normality were nonsignificant for each item. Given these findings, the normality assumption was met for this sample, and therefore, no data transformations were necessary or utilized for the confirmatory factor analysis.

We began the CFA by fitting this model with six items for each facet (i.e., hope, resilience, optimism, and self-efficacy) and then fit each of the four dimensions to the higher-order PsyCap. Results indicated the following estimates of model fit: SRMR $=.051$, RMSEA $=.046, \mathrm{CFI}=.934$. Hu and Bentler (1999) suggest that cutoffs close to or below .08 for SRMR, .06 for RMSEA, 
and at or above .95 for CFI indicate adequate fit. Therefore, using the combinatorial rule that two of three indices should be within acceptable ranges for adequate model fit ( $\mathrm{Hu} \&$ Bentler, 1999), overall fit was deemed adequate. Furthermore, each of the factor loadings was significant on their respective latent factor at $p<.01$. The confirmatory factor analysis in Study 1 supports the proposed higher-order factor structure for the overall PsyCap measure. These results provide initial psychometric support for the PsyCap measure and its use in testing the hypotheses in Study 2.

To add further stringency to our analyses across heterogeneous samples and as a result lend further measurement support for the results obtained from our hypothesis testing, we also conducted CFA on both organizational samples utilized in Study 2. Because the two organizational sample sizes were below those normally utilized for SEM techniques, we combined the two samples to conduct this second CFA. Similar to what was found in the CFA for Sample 2 of Study 1, results for this CFA were as follows: SRMR $=.056, \mathrm{RMSEA}=.048, \mathrm{CFI}=.924$. Using the same criteria as before, these latter results provide additional support for the higher-order factor structure for the overall PsyCap measure.

In addition to the multiple CFAs, we conducted a competing models analysis to more directly examine the proposition that PsyCap may be an underlying construct described as a higher-order factor. The higher-order factor model described above and competing three-factor and one-factor models were subjected to a significance test of difference using chi square. Specifically, we compared the hypothesized higher-order model with each of the four facets loading to the higher-order factor against four competing models including multiple three-factor models, which combined various facets as well as a single-factor model in which all items were loaded to one latent PsyCap factor. Table 1 shows that the hypothesized higher-order factor model fits the data better than the three- and one-factor competing models across both samples. Results from these model comparisons supported the proposed higher-order positive psychological factor (PsyCap).

\section{PsyCap Measure Validity and Stability}

Beyond assessing the factor structure of the PsyCap scale, we also empirically examined its discriminant, convergent, and criterion validity. First, we generated a correlation matrix of discriminators with PsyCap from the second sample of Study $1(N=404)$, which are reported in Table 2. PsyCap was not related to age, education, Agreeableness, or Openness, but had a strong positive relationship with core self-evaluations and a moderate relationship with Extraversion and Conscientiousness. To better explicate the unique sources of variance between PsyCap, core self-evaluations, and related personality traits, 


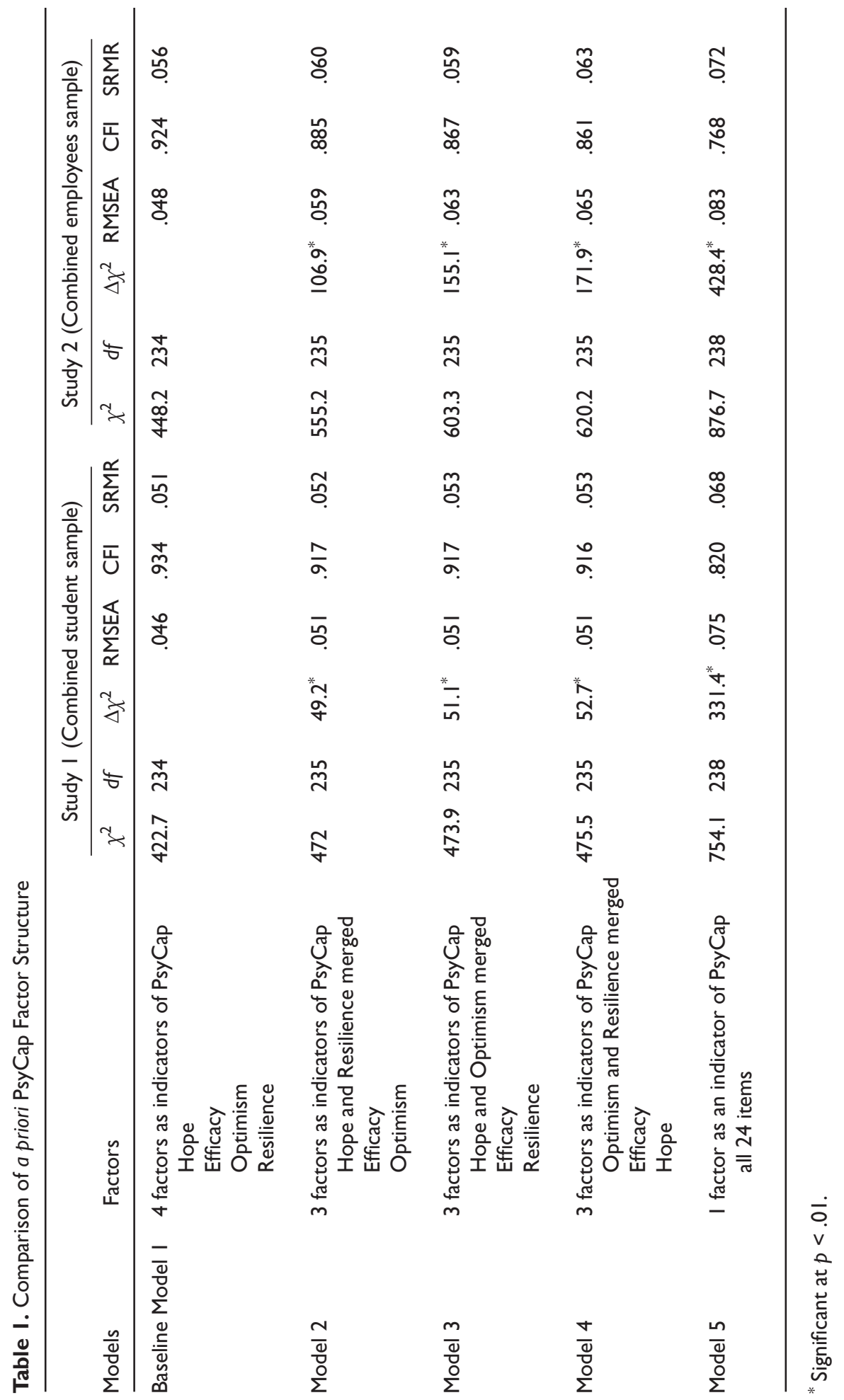




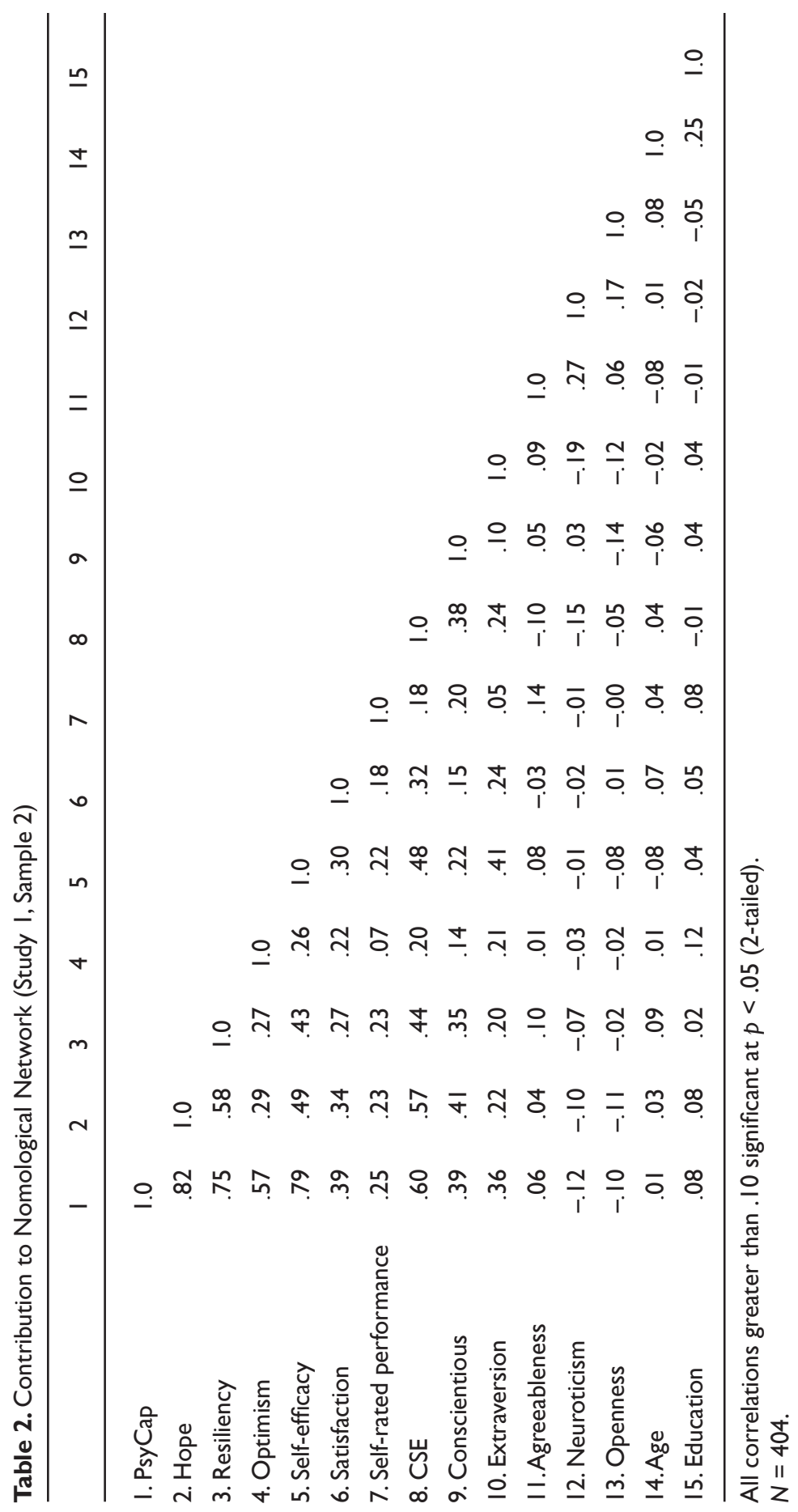


we utilized a series of correlation comparisons and hierarchical regressions to examine how PsyCap related to performance outcomes relative to these other variables.

Using data collected in Study 1, we compared the proposed PsyCap measure with three widely recognized trait-like measures: core self-evaluations ( $a=.81$, Judge \& Bono, 2001; Judge, Erez, Bono, \& Thoresen, 2003; Judge et al., 2004), Extraversion ( $a=.77)$, and Conscientiousness ( $a \mathrm{~F}=.57$, Gosling, Rentfrow, \& Swann, 2003). The core self-evaluations measure consists of 12 items developed by Judge and colleagues (2003), with three items each measuring locus of control, Neuroticism, self-esteem, and generalized selfefficacy. The Big Five measure used in this study was the short version (10 items) developed by Gosling and colleagues (2003) to be used in conjunction with larger surveys. We chose these two measures for the analysis because each has been shown to be positively related to desirable organizational outcomes (e.g., see Judge et al., 2003; Vinchur, Schippman, Switzer, \& Roth, 1998). In addition, Extraversion and Conscientiousness demonstrated the strongest relationship with PsyCap. Nevertheless, these data must be interpreted with caution because longer scales were not used and because of the relatively low reliability reported for Conscientiousness. Nevertheless, by using these two personality traits we can begin to better determine the extent to which PsyCap predicts variance beyond personality. We used the criterion variables of job satisfaction and affective organizational commitment for these analyses.

First, in the Study 1 sample, Conscientiousness $(r=.15, p<.01)$, Extraversion $(r=.24, p<.001)$, and core self-evaluation $(r=.32, p<.001)$ were all correlated with job satisfaction. Nevertheless, the correlation $(r=.39, p<.001)$ between the PsyCap measure and job satisfaction was higher than each of these three trait-like measures. A two-tailed Steiger's Z-test was then used to determine the significance of the differences. Results showed that PsyCap was slightly more strongly related to job satisfaction, yet not significantly $(p<.10)$ than core self-evaluations, but PsyCap was significantly stronger $(p<.001)$ than both Conscientiousness and Extraversion.

To examine the unique variance contributed by PsyCap in predicting job satisfaction, we used hierarchical regression analysis. In Step 1, we entered Conscientiousness, Extraversion, and core self-evaluation in a regression model followed by the PsyCap composite in Step 2. Although the regression model without the PsyCap composite was significant $\left(R^{2}=.13, p<.001\right)$, the change in $R^{2}$ was also significant $\left(\Delta R^{2}=.04, p<.001\right)$ demonstrating that PsyCap predicted unique variance in job satisfaction beyond the two personality traits and core self-evaluations. In the final regression model, the standardized beta weight for PsyCap was the largest in the model. This analy- 
sis provides some preliminary discriminant validity support between PsyCap and other constructs such as personality traits (Conscientiousness and Extraversion) and core self-evaluations, as well as criterion validity for PsyCap with job satisfaction.

We followed the same procedure for affective organization commitment (the most relevant commitment outcome, see Allen \& Meyer, 1996), in which we found that the correlation with the PsyCap $(r=.36, p<.001)$ was again larger than the other trait-like variables of Conscientiousness $(r=.11, p<.05)$, Extraversion $(r=.02, p>.05)$ and core self-evaluations $(r=.10, p>.05)$. Similar to the analyses with job satisfaction, we used a two-tailed Steiger's Z-test to determine the significance of the difference. Results indicated the PsyCap was related to affective organizational commitment significantly stronger $(p$ $<$.001) than core self-evaluations, Conscientiousness, and Extraversion. Although the regression model that included core self-evaluations, Extraversion, and Conscientiousness as predictors without the PsyCap was again significant $\left(R^{2}=.02, p<.05\right)$, the change in $R^{2}$ was also significant $\left(\Delta R^{2}=.13, p\right.$ $<.001)$. In the final regression model the beta weight for the PsyCap was the largest in the model, indicating that PsyCap was once again the greatest contributor to predicting, in this case, affective organizational commitment.

Overall, these findings provide preliminary evidence that PsyCap accounts for unique variance beyond recognized trait-like personality and core self-evaluations when predicting job satisfaction and affective organizational commitment. Nevertheless, given that the large correlation between core selfevaluation and PsyCap could be heavily influenced by common method variance (Podsakoff et al., 2003), we conducted some further analyses.

To understand better the relationship between core self-evaluations and PsyCap as well as the stability of the PsyCap measure over time, we utilized a third sample of management students $(N=174)$. To accumulate longitudinal data, at three points in time separated by 7-10 days each these participants completed at each point the 24-item PsyCap questionnaire, the core self-evaluations scale (Judge et al., 2003), the 10-item Conscientiousness scale (Goldberg et al., 2006), and a 10-item positive emotions scale (Fredrickson, Tugade, Waugh, \& Larkin, 2003). The total time period of data collection was 4 weeks. Each instrument demonstrated adequate reliabilities $(a \geq .70)$ at each data collection.

As indicated in our introductory comments, core self-evaluations (Judge et al., 2003) are considered to be a relatively stable, trait-like higher-order construct. Given the self-focused and higher-order nature of both core self-evaluations and the proposed PsyCap, we expected them to be somewhat related (convergence), but still distinct (discriminant). Results indicated a range of correlations between all time points between PsyCap and CSE from $r=.10$ 
$(p>.05)$ to $r=.32(p<.001)$. After correcting for unreliability, this range increased to $r=.12(p>.05)$ to $r=.46(p<.001)$. Overall, we examined nine bivariate relationships (PsyCap at Time 1 with CSE at Time 1, 2, and 3 and the same for PsyCap at Time 2 and Time 3). Six of the nine bivariate relationships demonstrated significant relationships. Hence, there is evidence for convergence in that PsyCap was related to core self-evaluations. Nevertheless, there is also evidence that PsyCap and core self-evaluations are empirically distinct as shown by the relatively low correlations and regression analyses (see above) offering support for discriminant validity (Kline, 2005).

Finally, to determine the degree of stability of the PsyCap measure over time, we calculated test-retest reliabilities on the PsyCap instrument compared with core self-evaluations, Conscientiousness, and positive emotions. Test-retest statistics were calculated across each point in time and averaged. After disattentuating for internal reliability, the corrected test-retest statistics for Conscientiousness (.76) and core self-evaluations (.87) both showed relatively higher stability than the PsyCap measure (.52) and the positive emotions measure (.46). In sum, these results support not only that PsyCap and core self-evaluations are related yet distinct constructs, but also there is at least preliminary empirical evidence that PsyCap may be "state-like" and in this way distinct from the "trait-like" core self-evaluations and personality traits, as well as the positive emotional states.

\section{Hypotheses Testing Results}

To test our Study 2 hypotheses, we utilized the PsyCap measure and organizationally determined performance measures of employees from the hightech manufacturing firm (Sample 1) and insurance service firm (Sample 2). As shown in Table 3, in which we provide all of the relationships for the individual and overall PsyCap scales, although there were mixed results for the four individual components, full support was found for Hypothesis 1 regarding the overall PsyCap having a significant positive relationship with both performance $(r=.33, p<.01$ in the manufacturing firm and $r=.22, p<.01$ in the service firm) and satisfaction ( $r=.32, p<.01$ in the manufacturing firm and $r$ $=.53, p<.01$ in the service firm).

For Hypothesis 2 concerning overall PsyCap having a relatively stronger relationship with performance and satisfaction than the individual components, following the approach taken by Judge and colleagues (Erez \&Judge, 2001; Judge, Erez, Bono, \& Thoresen, 2003), we conducted what is termed a usefulness analysis (Darlington, 1990). Given the importance of a new scale to show incremental validity beyond existing measures, usefulness analysis provides evidence for the utility of a measure in predicting variance in outcome 
Table 3. Intercorrelations Among Study 2 Variables Using Performance and Job Satisfaction

\begin{tabular}{|c|c|c|c|c|c|c|c|}
\hline & I. & 2. & 3. & 4. & 5. & 6. & 7. \\
\hline \multicolumn{8}{|l|}{ Sample I } \\
\hline I. Hope ${ }^{a}$ & 1.0 & & & & & & \\
\hline 2. Resilience ${ }^{a}$ & $.47^{* *}$ & 1.0 & & & & & \\
\hline 3. Self-efficacy ${ }^{a}$ & $.51 * *$ & $.40 * *$ & 1.0 & & & & \\
\hline 4. Optimism ${ }^{a}$ & $.61^{* *}$ & $.49 * *$ & $.44 * *$ & 1.0 & & & \\
\hline 5. PsyCap a & $.83 * *$ & $.72 * *$ & $.78^{* *}$ & $.81 * *$ & 1.0 & & \\
\hline 6. Performance ${ }^{a}$ & $.24 * *$ & $.22 *$ & $.35 * *$ & .16 & $.33 * *$ & 1.0 & \\
\hline 7. Job satisfaction ${ }^{a}$ & $.35 * *$ & .17 & $.30 * *$ & .17 & $.32^{* *}$ & $.27^{*}$ & 1.0 \\
\hline
\end{tabular}

Sample 2

\begin{tabular}{lllllllll} 
I. Hope & b & 1.0 & & & & & & \\
2. Resilience $^{\mathrm{b}}$ & $.54^{* *}$ & 1.0 & & & & & \\
3. Self-efficacy $^{\mathrm{b}}$ & $.50^{* *}$ & $.42^{* *}$ & 1.0 & & & \\
4. Optimism $^{\mathrm{b}}$ & $.42^{* *}$ & $.34^{* *}$ & $.61^{* *}$ & 1.0 & & \\
5. PsyCap $^{\mathrm{b}}$ & $.81^{* *}$ & $.71^{* *}$ & $.81^{* *}$ & $.78^{* *}$ & 1.0 & & \\
6. Performance $^{\mathrm{b}}$ & $.29 * *$ & .16 & .11 & .11 & $.22^{*}$ & 1.0 & \\
7. Job satisfaction $^{\mathrm{b}}$ & $.30^{* *}$ & .12 & $.58^{* *}$ & $.62^{* *}$ & $.53^{* *}$ & $.22^{*}$ & 1.0 \\
\hline
\end{tabular}

PsyCap = Core Positive Psychological Capital consisting of hope, resilience, self-efficacy, and optimism.

a Study 2, Sample I (manufacturing sample, $N=115$ ).

b Study 2, Sample 2 (services sample, $N=144$ ).

$* p<.05$ (2-tailed).

$* * p<.01$ ( 2 -tailed).

variables beyond existing measures. More specifically in this case, the utility of the composite PsyCap was compared with each of the individual dimensions to determine whether it was more "useful" than the existing measures of each facet. This process of comparing the composite to each component was also used by Judge and colleagues (2003) in assessing core self-evaluations.

Results of the usefulness analysis reported in Table 4 shows that in general PsyCap is more consistently related to both performance and satisfaction than each of the individual components. In this usefulness analysis, each individual component was first entered into a regression to predict the criterion variable. Then, the overall PsyCap was entered into the regression to determine the increase in multiple correlation value. These results were then compared with the reverse situation where overall PsyCap was entered first into the regression followed by each individual component variable. As can be seen, the overall PsyCap generally across both samples increased the multiple correlation value above and beyond its individual components. In the few instances where the individual component was higher, there was no consistency in terms of which facet outperformed the composite index. For example, 


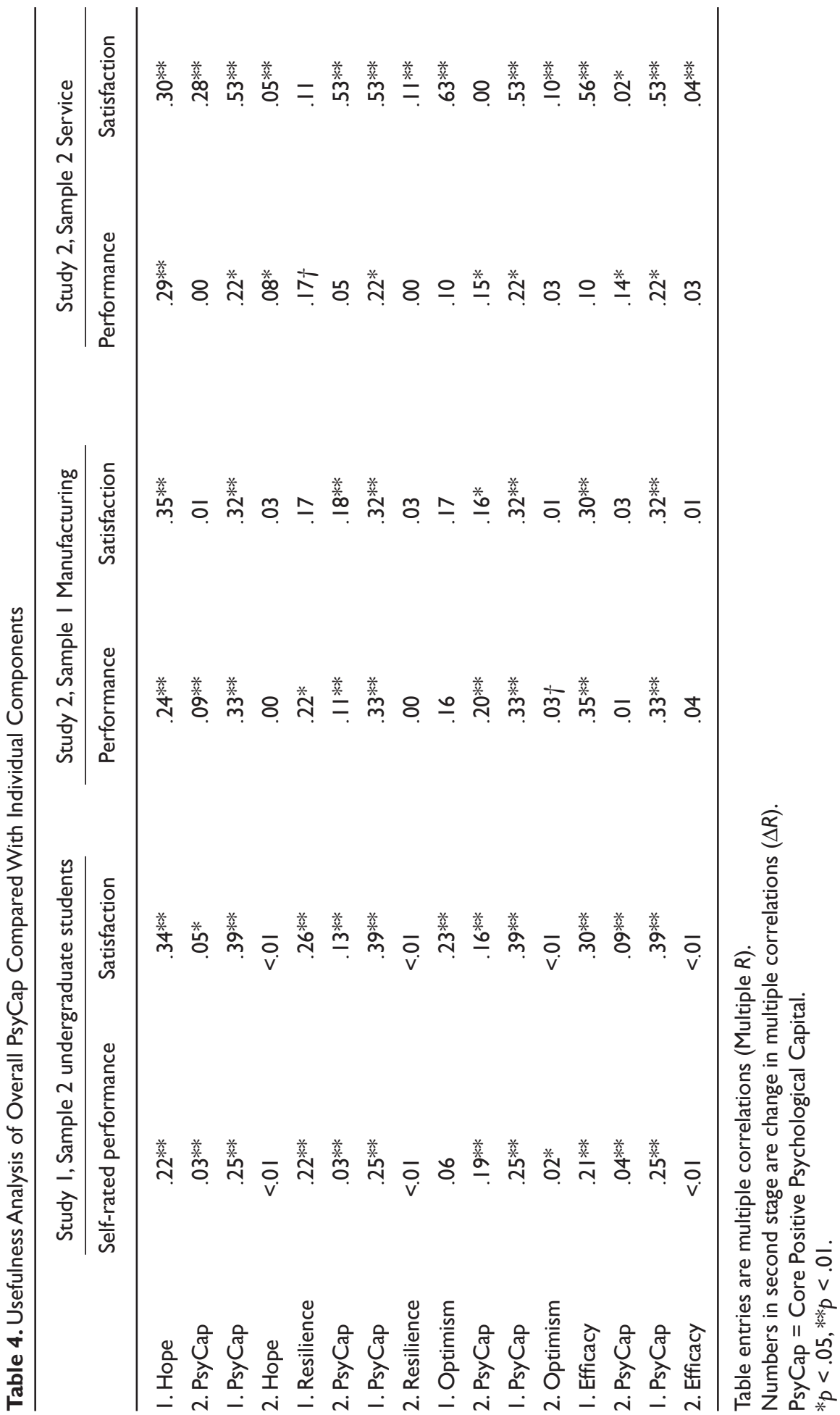


in Study 1, Sample 2, only hope contributed additional variance to the selfrated performance composite and none of the facets added additional variance to the satisfaction variable. In addition, in the high-tech firm sample in Study 2, none of the individual facets in the performance equation added significantly $(p<.05)$ to the model with only PsyCap entered, whereas in the services firm sample only hope $(p<.05)$ did. On the other hand, for the high-tech manufacturing sample, none of the individual facets added to the satisfaction equation and for the services sample hope, resilience, and optimism did with only PsyCap entered. Taken as a whole, this usefulness analysis lends support for Hypothesis 2.

\section{Discussion}

State-like positive psychological constructs have recently been identified based on the considerable theoretical and research foundation work in positive psychology (e.g., see Peterson, 2006; Peterson \& Seligman, 2004; Seligman, Steen, Park, \& Peterson, 2005; Snyder \& Lopez, 2002) and positive organizational behavior (e.g., Luthans, 2002a, 2002b; Luthans \& Youssef, in press, 2007; Luthans, Youssef, \& Avolio, 2007; Nelson \& Cooper, 2007; Turner, Barling, \& Zaharatos, 2002; Wright, 2003). Here, PsyCap is proposed as a measurable higher-order construct indicated by the components of hope, optimism, self-efficacy, and resilience. Confirmatory factor analyses provided initial support for a 24-item PsyCap measure, and model comparisons showed that this PsyCap can be represented as a higher-order factor indicated by the four facets.

Although the major focus of Study 1 was to provide initial psychometric support for the PsyCap measure, the follow-up Study 2 provided further psychometric support for the PsyCap scale through confirmatory factor analysis with heterogeneous samples of organizational participants in high-tech manufacturing and service. The Study 2 results provided only mixed support for the four individual PsyCap components in terms of their respective relationships with performance and satisfaction. Nevertheless, the two study hypotheses that there was a positive relationship between PsyCap and performance and job satisfaction and that PsyCap was a better predictor of these outcomes than the individual components were supported.

We believe the main theoretical contribution of this study is the preliminary support for PsyCap as a higher-order, core-positive factor indicated by each of the recognized constructs of self-efficacy, hope, optimism, and resilience. In particular, this research adds to previous theoretical considerations for such a core construct (e.g., Luthans \& Youssef, 2007; Luthans, Youssef, \& Avolio, 2007) that have drawn from psychological resource theory (Hobfoll, 2002) and the broaden-and-build theory from positive emotions (Fredrickson, 
2001). In addition, the findings of this study of a core positive psychological construct have important implications for future research and practical applications. Nevertheless, before specifically examining these implications, some of the limitations of the studies must be noted.

\section{Study Limitations}

A potential limitation in Study 1 lies in the common criticism of utilizing college students as research subjects. To address this issue, we conducted Study 2 using full-time employed organizational participants in both hightech manufacturing and service firms to further examine the factor structure underlying PsyCap and to test our study hypotheses. Related to the use of student samples in this study is also the limitation of their self-reported performance indices. Although the hypotheses tests only included organizationgenerated, supervisor-rated, or objective performance evaluations, the self-reported performance indices used in assessing the measure in Study 1 may be limited in terms of social desirability. Beyond the threat of social desirability, self-rated performance may also share conceptual overlap with some of the PsyCap questionnaire items such as self-efficacy.

Another potential limitation concerns the initial validation results of the PsyCap measure with the student sample. Because this sample does not represent the heterogeneity of samples that will use this measure, results concerning the factor structure of this instrument should be still viewed as preliminary. To begin to address this limitation, we conducted another confirmatory factor analysis using the employee samples collected as part of Study 2. Results were replicated providing evidence of the four-factor structure and higher-order PsyCap core factor holding across heterogeneous, full-time adult employee samples. Nevertheless, there is still a need to provide further evidence to justify the construct validity of this core construct using other samples in the United States, as well as across different cultural settings.

We pursued a strategy to modify existing scales and surveys from the published literature to construct our measure. The advantage of using this strategy was building on earlier psychometric work with established scales. The disadvantage is that there may be even better items to tap into each of these respective constructs that require additional item generation and validation. With the strength of evidence provided in this study for the existence of PsyCap, we hope future researchers will explore whether new items can improve the measurement properties of the PsyCap instrument tested here, as well as using a broader range of sample contexts.

The last, but perhaps most important, limitation recognized in this research is the cross-sectional research design with correlational relationships 
used to assess the relationship of PsyCap with performance and job satisfaction. One drawback of such research designs is that because of issues such as common method variance, the relationships between each of the four components may be artificially increased. A longitudinal research design may uncover divergence among components over time. Unfortunately, except for the test-retest analysis for the stability of the PsyCap measure, we could not examine the role of time as a factor in these studies. Due to the way the data were collected on PsyCap and performance outcomes, we can also not determine the nature of cause and effect. It is possible that knowledge of their own prior performance outcomes may have affected the way in which participants ended up rating their PsyCap.

\section{Implications and Conclusion}

Findings from this study would seem to have many practical implications for the development and management of human resources' motivational propensities in today's workplace. Employees who are more hopeful, optimistic, efficacious, and resilient may be more likely to "weather the storm" of the type of dynamic, global environmental contexts confronting most organizations today better than their counterparts with lower PsyCap. Although continued investment in financial, human, and social capital is certainly necessary, it may no longer be sufficient in this environment. Initial utility analysis indicates that the investment in psychological capital may yield very substantial returns beyond the other more traditional forms of capital investment (Luthans et al., 2006; Luthans et al., 2007; Youssef \& Luthans, in press).

Besides investment in and development of overall human resources, another implication would be further focus on linking PsyCap to how leaders impact their followers. For example, Avolio and Luthans (2006) have recently proposed that leaders who are more authentic and transformational will have a more positive impact on their followers' motivational tendencies. Indeed, the leadership literature is replete with discussions linking historical leaders with each of the components of PsyCap, yet we are not aware of any research to date that has tested these relationships in combination as found in this study. Paralleling the work here, a great deal of the research on leadership has focused on correcting what's wrong with leaders, as opposed to examining the degree of PsyCap associated with effective leaders.

In conclusion, this study provides initial evidence that positive constructs such as hope, resilience, efficacy, and optimism may have a common core that we have labeled for convenience as psychological capital that can be measured and related to performance and satisfaction. For the future, research may uncover other such positive constructs that meet the inclusion criteria 
for psychological capital that can be assessed, developed, and leveraged for performance improvement.

\section{References}

Adams VH, Snyder CR, Rand KL, King EA, Sigman DR, Pulvers KM. (2002). Hope in the workplace. In Giacolone R, Jurkiewicz C (Eds.), Workplace spirituality and organization performance. New York: Sharpe.

Allen NJ, Meyer JP. (1990). The measurement and antecedents of affective, continuance and normative commitment to the organization. Journal of Occupational and Organizational Psychology, 63, 1-18.

Allen NJ, Meyer JP. (1996). Affective, continuance, and normative commitment to the organization: An examination of construct validity. Journal of Vocational Behavior, 49, 252-276.

Allen BP, Potkay CR. (1981). On the arbitrary distinction between states and traits. Journal of Personality and Social Psychology, 41, 916-928.

Arnett JJ. (2000). Emerging adulthood: A theory of development from the late teens through the twenties. American Psychologist, 55, 469-480.

Avolio BJ, Luthans F. (2006). The high impact leader: Moments matter for accelerating authentic leadership development. New York: McGraw-Hill.

Avolio BJ, Bass BM, Jung D. (1999). Re-examining the components of transformational and transaction using multi-factor leadership questionnaire. Journal of Occupational and Organizational Psychology, 72, 441-462.

Bandura A. (1997). Self-self efficacy: The exercise of control. New York: Freeman.

Bandura A. (1998). Personal and collective efficacy in human adaptation and change. In Adair JG, Belanger D, Dion KL (Eds.), Advances in psychological science, Vol. 1: Personal, social and cultural aspects (pp. 51-71). Hove, UK: Psychology Press.

Bandura A. (2000). Cultivate self-efficacy for personal and organizational effectiveness. In Locke EA (Ed.), The Blackwell handbook of principles of organizational behavior (pp. 120-136). Oxford, UK: Blackwell.

Bandura A, Locke EA. (2003). Negative self-self efficacy and goal effects revisited. Journal of Applied Psychology, 88, 87-99.

Barrick MR, Mount MK. (1991). The Big Five personality dimensions and job performance: A meta-analysis. Personnel Psychology, 44, 1-26.

Bono JE, Judge TA. (2003). Self concordance at work: Toward understanding the motivational effects of transformational leaders. Academy of Management Journal, 46, 554-571.

Bryant FB, Cvengros JA. (2004). Distinguishing hope and optimism. Journal of Social and Clinical Psychology, 23, 273-302.

Carifio J, Rhodes L. (2002). Construct validities and the empirical relationships between optimism, hope, self-efficacy, and locus of control. Work, 19, 125-136.

Carver CS, Scheier MS. 2005. Optimism. In Snyder CR, Lopez SJ (Eds.), Handbook of positive psychology (pp. 231-243). Oxford, UK: Oxford University Press.

Chamberlain K, Zita S. (1992). Stability and change in subjective well-being over short periods. Social Indicators Research, 20,101-117.

Conley JJ. (1984). The hierarchy of consistency: A review and model of longitudinal findings on adult individual differences in intelligence, personality, and self-opinion. Personality and Individual Differences, 5, 11-25.

Cropanzano R, Wright TA. (1999). A five-year study of change in the relationship between wellbeing and job performance. Consulting Psychology Journal, 51, 252- 265. 
Darlington RB. (1990). Regression and linear models. New York: McGraw-Hill.

Erez A, Judge TA. (2001). Relationship of core self-evaluations to goal setting, motivation, and performance. Journal of Applied Psychology, 86, 1270-1279.

Fredrickson BL. (2001). The role of positive emotions in positive psychology: The broaden-andbuild theory of positive emotions. American Psychologist, 56, 218-226.

Fredrickson BL, Joiner T. (2002). Positive emotions trigger upward spirals toward emotional wellbeing. Psychological Science, 13, 172-175.

Fredrickson BL, Tugade MM, Waugh CE, Larkin, G. (2003). What good are positive emotions in crises? Journal of Personality and Social Psychology, 84, 365-376.

Goldberg LR, Johnson JA, Eber HW, Hogan R, Ashton MC, Cloninger CR, et al. (2006). The International Personality Item Pool and the future of public-domain personality measures. Journal of Research in Personality, 40, 84-96.

Gosling SD, Rentfrow PJ, Swann WB. (2003). A very brief measure of the Big-Five personality domains. Journal of Research in Personality, 37, 504-528.

Hackman JR, Oldham GR. (1980). Work redesign. Reading, MA: Addison-Wesley.

Herzberg F. (1966). Work and the nature of man. Cleveland, OH: World.

Hinken TR. (1995). A review of scale development practices in the study of organizations. Journal of Management, 21, 967-988.

Hobfoll S. (2002). Social and psychological resources and adaptation. Review of General Psychology, 6, 307-324.

Hu L, Bentler PM. (1999). Cutoff criteria for fit indices in covariance structure analysis: Conventional criteria versus new alternatives. Structural Equation Modeling, 61, 1-55.

Jensen SM, Luthans F. (2006). Relationship between entrepreneurs' psychological capital and their authentic leadership. Journal of Managerial Issues, 18, 254- 273.

Judge TA, Bono JE. (2000). Five factor model of personality and transformational leadership. Journal of Applied Psychology, 85, 751-765.

Judge TA, Bono JE. (2001). Relationship of core self-evaluation traits-self-esteem, generalized self efficacy, locus of control, and emotional stability - with job-satisfaction and performance: A meta-analysis. Journal of Applied Psychology, 86, 80- 92.

Judge TA, Erez, A., Bono JE, Thoresen CJ. (2003). The core self-evaluation scale: Development of a measure. Personnel Psychology, 56, 303-331.

Judge TA, Van Vianen AEM, DePater IE. (2004). Emotional stability, core-evaluations, and job outcomes. Human Performance, 17, 325-346.

Kersting K. (2003). Turning happiness into economic power. Monitor on Psychology, 34(11), 26.

Klein KJ, Dansereau F, Hall RJ. (1994). Level issues in theory development, data collection and analysis. Academy of Management Review, 19, 195-229.

Kline RB. (2005). Principles and practice of structural equation modeling. New York: Guilford.

Larson M, Luthans F. (2006). Potential added value of psychological capital in predicting work attitudes. Journal of Leadership and Organizational Studies, 13, 44-61.

Law KS, Wong C, Mobley WH. (1998). Toward a taxonomy of multidimensional constructs. Academy of Management Review, 23, 741-755.

Luthans F. (2002a). The need for and meaning of positive organizational behavior. Journal of Organizational Behavior, 23, 695-706.

Luthans F. (2002b). Positive organizational behavior: Developing and managing psychological strengths. Academy of Management Executive, 16, 57-72.

Luthans F, Avey JB, Avolio BJ, Norman S, Combs G. (2006). Psychological capital development: Toward a micro-intervention. Journal of Organizational Behavior, 27, 387-393. 
Luthans F, Avey JB, Patera, JL. (in press). Experimental analysis of a web-based intervention to develop positive psychological capital. Academy of Management Learning and Education.

Luthans F, Avolio BJ. (2003). Authentic leadership: A positive developmental approach. In Cameron KS, Dutton JE, Quinn RE (Eds.), Positive organizational scholarship (pp. 241-261). San Francisco: Barrett-Koehler.

Luthans F, Avolio B, Walumbwa F, Li W. (2005). The psychological capital of Chinese workers: Exploring the relationship with performance. Management and Organization Review, 1, 247-269.

Luthans F, Jensen SM. (2002). Hope: A new positive strength for human resource development. Human Resource Development Review, 1, 304-322.

Luthans F, Youssef CM. (2004). Human, social, and now positive psychological capital management. Organizational Dynamics, 33, 143-160.

Luthans F, Youssef CM. (2007). Emerging positive organizational behavior. Journal of Management, 33, 321-349.

Luthans F, Youssef CM. (in press). Positive workplaces. In Snyder CR, Lopez SJ (Eds.), Handbook of positive psychology (2nd ed.). New York: Oxford University Press.

Luthans F, Youssef CM, Avolio BJ. (2007). Psychological capital. New York: Oxford University Press.

Maddi SR. (1987). Hardiness training at Illinois Bell Telephone. In Opatz P (Ed.), Health promotion evaluation (pp. 101-115). Stevens Point, WI: National Wellness Institute.

Magaletta PR, Oliver JM. (1999). The hope construct, will and ways: Their relations with self-efficacy, optimism and well-being. Journal of Clinical Psychology, 55, 539-551.

Maslow AJ. (1954). Motivation and personality. New York: Harper \& Row.

Masten AS. (2001). Ordinary magic: Resilience processes in development. American Psychologist, $56,227-239$.

Masten AS, Reed MGJ. (2002). Resilience in development. In Snyder CR, Lopez SJ (Eds.), Handbook of positive psychology (pp. 74-88). Oxford, UK: Oxford University Press.

Maurer TJ, Pierce HT. (1998). A comparison of Likert scale and traditional measures of self-efficacy. Journal of Applied Psychology, 83, 324-329.

McGregor D. (1960). The human side of enterprise. New York: McGraw-Hill.

Nelson D, Cooper CL. (Eds.) (2007). Positive organizational behavior: Accentuating the positive at work. Thousand Oaks, CA: Sage.

Parker S. (1998). Enhancing role-breadth self efficacy: The roles of job enrichment and other organizational interventions. Journal of Applied Psychology, 83, 835-852.

Pedhazer EJ, Schmelkin LP. (1991). Measurement, design and analysis: An integrated approach. Hillsdale, NJ: Erlbaum.

Peterson C. (2000). The future of optimism. American Psychologist, 55, 44-55.

Peterson C. (2006). A primer in positive psychology. New York: Oxford University Press.

Peterson C, Seligman ME. (2004). Character strengths and virtues. Oxford, UK: Oxford University Press.

Peterson S, Luthans F. (2003). The positive impact of development of hopeful leaders. Leadership and Organization Development Journal, 24, 26-31.

Podsakoff PM, MacKenzie SC, Lee J, Podsakoff NP. (2003). Common method biases in behavioral research: A critical review of the literature and recommended remedies. Journal of Applied Psychology, 88, 879-903.

Richardson GE. (2002). The metatheory of resilience and resiliency. Journal of Clinical Psychology, $58,307-321$. 
Scheier MF, Carver CS. (1985). Optimism, coping, and health: Assessment and implications of generalized outcome expectancies. Health Psychology, 4, 219-247.

Schneider SI. (2001). In search of realistic optimism. American Psychologist, 56, 250-263.

Schwab DP. (1980). Construct validity in organizational behavior. Research in Organizational Behavior, 2, 3-43.

Seligman MEP. (1998). Learned optimism. New York: Pocket Books.

Seligman MEP, Steen TA, Park N, Peterson C. (2005). Positive psychology progress: Empirical validation of interventions. American Psychologist, 60, 410-421.

Sheldon K, King L. (2001). Why positive psychology is necessary. American Psychologist, 56(3), 216-217.

Sherer M, Maddux JE, Mercandante B, Prentice-Dunn S, Jacobs B, Rogers RW. (1982). The selfefficacy scale: Construction and validation. Psychological Reports, 51, 663-671.

Shifren K, Hooker K. (1995). Stability and change in optimism. Experimental Aging Research, 21, 59-76.

Snyder CR. (2000). Handbook of hope. San Diego: Academic Press.

Snyder CR. (2002). Hope theory: Rainbows in the mind. Psychological Inquiry, 13(4), 249-276.

Snyder CR, Irving L, Anderson J. (1991). Hope and health: Measuring the will and the ways. In Snyder CR, Forsyth DR (Eds.), Handbook of social and clinical psychology (pp. 285-305). Elmsford, NY: Pergamon.

Snyder CR, Lopez S. (2002). Handbook of positive psychology. Oxford, UK: Oxford University Press.

Snyder CR, Sympson S, Ybasco F, Borders T, Babyak M, Higgins R. (1996). Development and validation of the state hope scale. Journal of Personality and Social Psychology, 70, 321-335.

Spreitzer GM. (1995). Psychological empowerment in the workplace: Dimensions, measurement, and validation. Academy of Management Journal, 38, 1442-1465.

Stajkovic A, Luthans F. (1998a). Self-self efficacy and work-related performance: A meta-analysis. Psychological Bulletin, 124, 240-261.

Stajkovic AD, Luthans F. (1998b). Social cognitive theory and self-self efficacy: Going beyond traditional motivational and behavioral approaches. Organizational Dynamics, 26, 62-74.

Tugade MM, Fredrickson BL, Barrett LF. (2004). Psychological resilience and positive emotional granularity. Journal of Personality, 72, 1161-1190.

Turner N, Barling J, Zaharatos A. (2002). Positive psychology at work. In Snyder CR, Lopez S (Eds.), Handbook of positive psychology (pp. 715-728). Oxford, UK: Oxford University Press.

Vinchur A, Schippman J, Switzer F, Roth P. (1998).A meta-analytic review of the predictors of job performance for salespeople. Journal of Applied Psychology, 83, 586-597.

Wagnild GM, Young HM. (1993). Development and psychometric evaluation of the resiliency scale. Journal of Nursing Management, 1(2), 165-178.

Watson D, Clark LA. (1984). Negative affectivity: The disposition to experience aversive emotional states. Psychological Bulletin, 96, 465-490.

Wright TA. (2003). Positive organizational behavior: An idea whose time has truly come. Journal of Organizational Behavior, 24, 437-442.

Wright TA. (2007). A look at two methodological challenges for scholars interesting in positive organizational behavior. In Nelson DL, Cooper CL (Eds.), Positive organizational behavior (pp. 177-190.). Thousand Oaks, CA: Sage.

Youssef CM, Luthans F. (in press). Positive organizational behavior in the workplace: The impact of hope, optimism and resiliency. Journal of Management.

Zuckerman M. (1983). The distinction between trait and state scales is not arbitrary. Journal of Personality and Social Psychology, 44, 1083-1086. 